Ozone is an intrinsically toxic gas and its hazardous employment has led to a poor consideration of ozone therapy. The aim of this review is to indicate that a wrong dogma and several misconceptions thwart progress: in reality, properly performed ozone therapy, carried out by expert physicians, can be very useful when orthodox medicine appears inadequate. The unbelievable versatility of ozone therapy is due to the cascade of ozone-derived compounds able to act on several targets leading to a multifactorial correction of a pathological state. During the past decade, contrary to all expectations, it has been demonstrated that the judicious application of ozone in chronic infectious diseases, vasculopathies, orthopedics and even dentistry has yielded such striking results that it is deplorable that the medical establishment continues to ignore ozone therapy.

Key words: Ozone, Oxidative stress, Antioxidants, Nitric oxide, Cytokines, Ozone tolerance

\section{Ozone as Janus: this controversial gas can be either toxic or medically useful}

\author{
Velio Bocci ${ }^{\mathrm{CA}}$
}

Department of Physiology, University of Siena, Via A. Moro, 53100 Siena, Italy

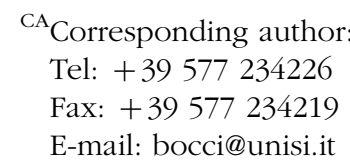

\section{Introduction}

I beg the readers' pardon if this review has been written in a personal way but it was meant to express the reflections of an old ozone therapist, even though the actual title was finally selected to emphasize the controversial actions of ozone.

In 1988, I was still interested in evaluating interferon (IFN) inducers and, by mere coincidence, I wondered whether ozone, like galactose oxidase and periodate, could induce the production of IFN- $\gamma$ on human blood mononuclear cells. Under very precise experimental conditions and using low doses of ozone, it could, but was a weak inducer compared with classical mitogens. Nonetheless I became fascinated by this natural gas that appeared to have controversial effects on earth and was hardly accepted in medicine. When Schoenbein discovered ozone in 1834, he considered it not only an oxidant, but also a disinfectant that unfortunately did not help him when, in 1868, he got a deadly anthrax infection. During the First World War it was used as a heroic therapy of gangrene and today it is widely employed for the sterilization of water. Wehrli and Steinbarth ${ }^{1}$ were the first to expose human blood to oxygen plus ultraviolet irradiation, but Wolff ${ }^{2}$ invented the simpler technique of exposing blood directly to a gas mixture composed of oxygen-ozone. Thus, was born the ozonated autohemotherapy $\left(\mathrm{O}_{3}\right.$-AHT) procedure that has been used millions of times. Since 1990, I realized that a standard method did not exist and even today some ozone therapists shamefully still use polyvinyl chloride autotransfusion bags and some evaluate the ozone effect by the change in color of blood (!) rather than the actual ozone concentration. Is $\mathrm{O}_{3}$-AHT an act of faith, then, a simple placebo treatment, or can it be an effective therapeutic treatment?

The purpose of this review is to present evidence that if we seriously tackle this problem, we can propose it as an efficacious therapy but, for doing so, we must know how ozone behaves within the biological system and its inherent advantages and disadvantages. It comes as no surprise that this topic today is dominated by prejudices and most ozone therapists believe that obstruction to this therapy comes from pharmaceutical industries, while in fact the main opponents are Health Authorities that do not care to assess its merit. As skepticism is antithetic to science, this paper aims to establish the truth.

\section{How can ozone act?}

For several years my collaborators and I have made an effort to establish the fate and effects of ozone when blood ex vivo is exposed to it. ${ }^{3}$ First, for in vitro studies, we established a standard method technically identical (except blood volume) to the classical $\mathrm{O}_{3}$-AHT performed in patients. Five millilitres of human blood is precisely exposed to $5 \mathrm{ml}$ of either pure oxygen (control) or to a gas mixture composed of both oxygen (95-99.9\%) and ozone (0.1-5\%). A modern medical generator, equipped with a photometer, can deliver precise ozone concentrations between 1 and $100 \mu \mathrm{g} / \mathrm{ml}$ where the ozone, relative to the oxygen concentration, varies between 0.1 and 5\%. Thus, there is a sort of 
stoichiometric relationship between ozone and blood that unavoidably has an individual variability in terms of hematocrit value, plasma antioxidant capacity and cell composition. Immediately after the gas addition, the blood, to avoid foaming, is gently mixed for $5 \mathrm{~min}$ and during this period both gases dissolve into the plasmatic water. While the $\mathrm{pO}_{2}$ values rise from about $40 \mathrm{mmHg}$ up to a plateau of $500 \mathrm{mmHg}$ within $5 \mathrm{~min}$ and remains stable, the solubilized ozone reacts instantaneously with the available antioxidant and polyunsaturated fatty acids present in plasma. The peroxidation reaction leads to the formation of hydrogen peroxide $\left(\mathrm{H}_{2} \mathrm{O}_{2}\right)$ and a mixture of lipoperoxides and then to end products, namely malonyldialdehyde and 4-hydroxy-2,3-alkenals of variable chain lengths, collectively known as lipid oxidation products (LOPs). ${ }^{4}$ Thus, within the most used range of ozone concentrations $(10-40 \mu \mathrm{g} / \mathrm{ml}$ of blood, equal to $0.21-0.84 \mathrm{mM}$ ), we distinguish two classes of compounds. The first is represented by the fastacting (half-life $<1$ sec) reactive oxygen species (ROS), among which $\mathrm{H}_{2} \mathrm{O}_{2}$ is the most important. The second is due to LOPs, measured as thiobarbituric acid-reactive substances (TBARS), that have a relatively long half-life and will act mostly on parenchymal cells, once the ozonated blood is reinfused into the donor. While we readily measure $\mathrm{H}_{2} \mathrm{O}_{2}$ after human plasma ozonation with a half-life of about $2 \mathrm{~min}$, its appearance in blood is so transitory that it cannot be assessed. $\mathrm{H}_{2} \mathrm{O}_{2}$ diffuses freely across plasma membranes and the enormous number of erythrocytes mops it up in a matter of seconds. Moreover blood cells, being particularly rich in reduced glutathione (GSH), catalase and glutathione peroxidase (GSH-Px), reduce $\mathrm{H}_{2} \mathrm{O}_{2}$ so quickly that its intracellular concentration is merely a $10 \%$ of the plasmatic one. ${ }^{5,6}$ This finding is important because intracellular concentrations above $1 \mu \mathrm{M}$ can be damaging. The formation of this $\mathrm{H}_{2} \mathrm{O}_{2}$ gradient is crucial for understanding how ozone acts: there is no doubt that blood must be exposed for about $5 \mathrm{~min}$ to an ozone dose that, although largely quenched by the plasmatic antioxidants, acting as sacrificial reactants (ascorbic and uric acids, free cysteine, GSH and $-\mathrm{SH}$ groups of albumin), elicits the formation of both ROS and LOPs indispensable for activating several biochemical, immunological and pharmacological mechanisms responsible for the biological and therapeutic effects. It must be emphasized that the ozone dose must suffice in inducing an acute, precise and transitory oxidative stress, and obviously either a very low or a high dose can be either ineffective (placebo) or toxic, respectively.

Two important questions needed to be answered. The first regarded the kinetics of total antioxidant status (TAS) levels ${ }^{7}$ after ozonation. Samples of normal human blood and relative plasmas were exposed to oxygen and two ozone concentrations: $40 \mu \mathrm{g} / \mathrm{ml}(0.84 \mathrm{mM})$ and $80 \mu \mathrm{g} / \mathrm{ml}(1.68 \mathrm{mM})$ (usual $1: 1 \mathrm{v}$ ratio). The TAS values of plasma was not modified by $\mathrm{O}_{2}$, while ozonation caused a significant decrease of $41 \%$ and $52 \%$, respectively, 10 min after the addition of ozone, when the decrease remained static and the double concentration of ozone did not further lower TAS levels. Then we tested the blood samples and were so puzzled by the results that we repeated the experiment twice to be really sure. As expected, oxygen was ineffective while two levels of ozonation ( 40 and $80 \mu \mathrm{g} / \mathrm{ml}$ ) caused a smaller decrease than in plasma (which was only $21 \%$ and 33\% respectively) after $1 \mathrm{~min}$; then, surprisingly, the TAS values began to rise progressively and returned to the pre-ozonation level within $20 \mathrm{~min}$. A reasonable interpretation of these results is that the presence of erythrocytes in the blood, in spite of ozonation, is able to regenerate antioxidants and quickly normalize TAS levels because erythrocytes can rapidly reconstitute the antioxidant reservoir. May et $a l^{8}$ and the data of Mendiratta et al. ${ }^{9}$ support this interpretation very well. We ascertained that in the same blood samples, ozonation had taken place because while TBARS ${ }^{10}$ increased three and five times, Protein Thiol Group levels ${ }^{11}$ decreased correspondingly but hemolysis remained negligible (no more than $0.4 \%$ ). Hemolysis increased progressively from 0.5 to $7 \%$ only when ozone concentrations rose from 100 up to $200 \mu \mathrm{g} / \mathrm{ml}$ per $\mathrm{ml}$ of blood.

The second question was whether ozonation of blood led to peroxidation of plasma membrane phospholipids. This was and still is a vexed question, because in the past several papers ${ }^{12-15}$ have reported that erythrocytes isolated from plasma, after washing and resuspension in a physiological medium, underwent structural change and intense hemolysis when exposed to ozone. It is unfortunate that these data greatly contributed to the belief in ozone toxicity; in fact, they are misleading because erythrocytes, deprived of plasma antioxidants and their natural albumin shield, are obviously very sensitive to ozone. The best proof of this erroneous belief is represented by Shinriki et al. ${ }^{16}$ and our data; ${ }^{17,18} 1 \mathrm{ml}$ of citrated human blood exposed to a concentrations as high as $100 \mu \mathrm{g} / \mathrm{ml}$ yielded only $0.2 \%$ and $0.5 \%$ hemolysis, respectively. Moreover, Shinriki et al. ${ }^{16}$ further demonstrated that TBARS are derived only from lipids present in plasma and not from erythrocytic membranes. In agreement with these results, they noted only an ozone-dependent depletion (about 20\%) of alpha tocopherol in plasma. Indeed other studies have clearly shown that when erythrocytes are protected by plasmatic antioxidants, peroxidation of membrane phospholipids is absent. ${ }^{19-23}$ In practical terms, it appears that only one (probably an old cell) out of 200-400 erythrocytes undergoes breakdown, 
at least in part due to manipulation rather than peroxidation.

These data establish that the ozone concentration must be precise, as today we are using ozone as a real drug. The sudden generation of $\mathrm{H}_{2} \mathrm{O}_{2}$ in the plasma and the transitory and far lower concentration of $\mathrm{H}_{2} \mathrm{O}_{2}$ in the cytoplasm mean that $\mathrm{H}_{2} \mathrm{O}_{2}$ is one of the ozone messengers, and its level is critical because it must be above a certain threshold to be effective but not too high to overwhelm antioxidants and become toxic. This state of the art has several implications:

- The ozonation procedure on blood induces only a calculated and very transitory oxidative stress that is promptly normalized by the powerful recycling of oxidized compounds to antioxidants.

- There is a negligible hemolysis, from the basic value of about $0.5 \%$ up to $1.2 \%$ if the anticoagulant is citrate and up to $1.8 \%$ if it is heparin. Shinriki et al. ${ }^{16}$ reported lower values than ours: from 0 to $0.27 \%$. However, as expected, washed erythrocytes yield a $10 \%$ value $^{13}$ and even higher values when blood is ozonized with excessive ozone doses (up to $200 \mu \mathrm{g} / \mathrm{ml}$ ). The enhanced hemolysis of heparinized blood is probably favored by a concomitant $\mathrm{Ca}^{2+}$ influx. These data establish that the ozone concentration should never exceed $80 \mu \mathrm{g} / \mathrm{ml}$ per $\mathrm{ml}$ of blood (1.68 $\mathrm{mM})$.

- Osmotic fragility of $\mathrm{Ca}^{2+}$-chelated blood is not evident even when an ozone concentration of $200 \mu \mathrm{g} / \mathrm{ml}$ is used and the hemolysis curve is moderately displaced to the left even in washed erythrocytes. ${ }^{13}$

- Levels of methemoglobin remain practically normal. Shinriki et al. ${ }^{16}$ reported a variation from $1.91 \pm 0.11 \%$ to $2.21 \pm 0.09 \%$ and we have always measured lower levels (i.e. about $1 \%$ in comparison to hemoglobin).

- The hematocrit value does not change, implying no modification of the erythrocytic volume due to osmotic swelling or erythrocytic lysis.

- At high levels of ozonation, there is a minimal loss of $\mathrm{K}^{+}$, which rapidly returns to normal. ${ }^{16}$

- The blood antioxidant system adequately protects erythrocytic enzymes such as $\mathrm{Na} / \mathrm{K}$ ATPase, acetylcholinesterase in blood exposed to ozone concentrations of $80 \mu \mathrm{g} / \mathrm{ml}^{16,24}$ as well as superoxide dismutase, GSH-Px, GSH reductase and glucose 6-phosphate dehydrogenase (G6PDH). ${ }^{25}$

\section{A concise summary of biological effects observed after ozone therapy}

\section{Erythrocytes}

These cells respond with an activation of glycolysis due to activation of the pentose phosphate pathway. We found increased adenosine triphosphate levels (from $1389 \pm 260$ to $1968 \pm 232 \mu \mathrm{M}$ ) in patients with age-related macular degeneration (ARMD) (atrophic form) after a therapeutic cycle (14 sessions) of $\mathrm{O}_{3}$-AHT. ${ }^{26}$ Moreover, Viebahn ${ }^{27}$ reported the same effect in athletes and elderly patients after rectal insufflation of $\mathrm{O}_{2}-\mathrm{O}_{3}$. Ozonation implies a small but consistent oxidation of GSH to glutathione disulfide, and GSH reductase utilizes the reduced form of the coenzyme nicotinamide adenine dinucleotide phosphate supplied by G6PDH to reduce glutathione disulfide to GSH, which indeed returns rapidly to the original level. ${ }^{28}$ The increase of 2,3-diphosphoglycerate varies depending on the basic level in ARMD patients and only those who had a low level showed a marked increase with therapy. Viebahn, ${ }^{27}$ after a longer cycle of therapy in elderly people, observed a significant increase. An increase of 2,3diphosphoglycerate level in oxyhemoglobin shifts to the right ( $\mathrm{p} 50$ value increases); its dissociation curve implies an increased delivery of $\mathrm{O}_{2}$ into the hypoxic tissues. The life-span of ozonated ${ }^{99}$ Tc-labeled erythrocytes and their uptake by liver and spleen are comparable with oxygenated erythrocytes. ${ }^{3}$

A problem still under study regards the generation of biochemically improved erythrocytes during prolonged ozone therapy. While ROS have an extremely short life, LOPs, during the reinfusion of ozonated blood, return into the donor's circulation. While they are fairly stable in vitro, they rapidly disappear from blood in vivo owing to considerable dilution into body fluids, degradation by aldehyde dehydrogenases, excretion into bile and urine, and uptake in various organs including bone marrow cells. This process is crucial for explaining the mechanism of ozone tolerance: during erythrogenesis, submicromolar LOP concentrations can upregulate the synthesis of antioxidant enzymes and indeed, after appropriate density gradient separation, we have found that young (lighter) erythrocytes contain more G6PDH than older (heavier) cells generated before the therapy. ${ }^{25}$ This result suggests that ozone therapy enhances the generation of erythrocytes with improved metabolic characteristics, a sort of 'supergifted erythrocytes' able to correct hypoxia in vascular diseases.

\section{Leukocytes}

These were the cells that we examined first as we hypothesized that ozone could act as an IFN- $\gamma$ 
inducer. $^{29}$ Since then we have shown ${ }^{30,31}$ that ozone behaves as a weak (compared with mitogens) cytokine (such as tumor necrosis factor- $\alpha$, interleukin-2, interleukin-6, interleukin-8, transforming growth factor- $\beta$ [TGF- $\beta]$ ) inducer. Several studies ${ }^{32-35}$ have confirmed that ozone can stimulate bronchoalveolar cells to release proinflammatory cytokines and eicosanoids. Thanks to parallel progress in understanding the role of antioxidants and redox regulation of gene transcription, it has been clarified that, among several signals, $\mathrm{H}_{2} \mathrm{O}_{2}$ is one of the most significant cytokine inducers. ${ }^{36}$ As already mentioned, after ozonation $\mathrm{H}_{2} \mathrm{O}_{2}$ freely diffuses into the leukocyte cytoplasm and activates specific protein kinases that, by phosphorylating I $\kappa \mathrm{B}$ bound to the nuclear factor- $\kappa \mathrm{B}$ allows the migration of the transcription heterodimer p50-p65 into the nucleus where it activates gene expression. ${ }^{37}$ Obviously $\mathrm{H}_{2} \mathrm{O}_{2}$ must reach a concentration able to activate the kinase without being instantaneously reduced by intracellular antioxidants. ${ }^{38}$ Therefore the relevance of the response depends on the levels of $\mathrm{H}_{2} \mathrm{O}_{2}$, which can act as either 'life or death' signals. The fact that ozone can either be a toxic or a useful signal depends on the minimal antioxidant capacity of the respiratory tract lining fluid, whereas blood has a very potent capacity. Our data in fact indicate that too little ozone (hence $\mathrm{H}_{2} \mathrm{O}_{2}$ ) is ineffective and too much (or too little antioxidants) can be toxic. During recent years we addressed the following questions: first, as ozone acts as a mild cytokine inducer, does reinfusion of ozonated blood modify the plasma cytokine level in vivo? Second, does the induction of oxidative stress proteins, particularly of heme-oxygenase I (HO-I), and of adaptation to the therapeutic oxidative stress have an immunomodulatory effect? And third, can we devise an optimal schedule for improving the immune reactivity in immunodepressed patients?

The classical $\mathrm{O}_{3}$-AHT, usually consisting of $225 \mathrm{ml}$ of blood (plus $25 \mathrm{ml}$ of $3.8 \%$ sodium citrate solution) treated with $225 \mathrm{ml}$ of gas $\left(\mathrm{O}_{2}-\mathrm{O}_{3}\right)$ with ozone concentrations ranging from an initial $20 \mu \mathrm{g} / \mathrm{ml}$ slowly scaled up to $40-50 \mu \mathrm{g} / \mathrm{ml}$ per $\mathrm{ml}$ of blood, continued for several months, twice weekly, is ideal for this purpose. A probable explanation is that, after each blood reinfusion, a small percentage of immune cells are activated and home in several organs: these cells release into the microenvironment cytokines that, in turn, prime or activate neighboring cells thus slowly reinforcing immune responses. Modifications of cytokine plasma levels are hardly detectable so that side effects like the flu-like syndrome, typically observed after administration of immunoadjuvants, are absent ${ }^{39}$ and actually most of patients report a sense of well-being during the therapy. There is a wealth of experimental data ${ }^{40-44}$ showing that both animals and plants can develop ozone tolerance by upregulating the expression of antioxidants, which can correct a chronic imbalance between excessive endogenous oxidation due to viral infections, cancer, chronic inflammations and depressed antioxidants. Both chronic hepatitis $\mathrm{C}$ virus and cancer patients have shown a marked improvement of their clinical conditions after several months of $\mathrm{O}_{3}$-AHT treatments, suggesting that this 'calculated and brief oxidative stress' truly merits the term 'therapeutic shock'.

\section{Platelets}

It is known that ROS can induce platelet activation and it was obvious to assume that blood ozonation, by generating $\mathrm{H}_{2} \mathrm{O}_{2}$, could cause it. ${ }^{45,46}$ Moreover $\mathrm{H}_{2} \mathrm{O}_{2}$ or other ROS can activate phospholipase C, phospholipase $\mathrm{A}_{2}$, cyclo-oxygenases and lipo-oxygenases and thromboxane synthetase, allowing a step increase of intracellular $\mathrm{Ca}^{2+}$, release of prostaglandin $E_{2}$, prostaglandin $F_{2 \alpha}$ and thromboxane $A_{2}$ with irreversible platelet aggregation. For these reasons we studied the behavior of either human platelet rich-plasma anticoagulated with heparin or citrate, either untreated or simply oxygenated, or ozonated at three concentrations $(20,40$ and $80 \mu \mathrm{g} / \mathrm{ml})$. Because the plasmatic $\mathrm{Ca}^{2+}$ level potentiates the ozone effect, we were not surprised to observe a rapid platelet aggregation in heparinized plasma particularly at the highest concentration. ${ }^{47}$ Consequently the release of several growth factors like platelet-derived growth factor $\mathrm{AB}$, TGF- $\beta 1$, interleukin- 8 and thromboxane $\times 2$ were significantly higher from heparinized platelets than $\mathrm{Ca}^{2+}$-free platelets. ${ }^{48}$ These results taught us that it is better to chelate $\mathrm{Ca}^{2+}$ for performing a safe autohemotherapy. Nonetheless the release of growth factors from $\mathrm{Ca}^{2+}$-free platelets is still important because the reinfusion of ozonated blood implies an elevation of plasma levels of TGF- $\beta$ that may explain why the healing of necrotic ulcers in hind limb ischemia due to atherosclerosis and diabetes markedly quickens during treatment with both parenteral $\left(\mathrm{O}_{3}\right.$-AHT) and topical treatments with ozonated water and oil. ${ }^{49,50}$

\section{Endothelial cells and the vascular system}

During the reinfusion of ozonated blood, the endothelium comes in contact with traces of LOPs that soon disappear in vivo. We $\mathrm{W}^{51}$ then investigated the effect of addition of ozonated ( 40 and $80 \mu \mathrm{g} / \mathrm{ml}$ ) human plasma to human endothelial cells in culture and we measured a significant increase of the critical relaxing factor $\mathrm{NO}^{\bullet}$ that was ozone dose dependent. The induction of nitric oxide synthase and the release of $\mathrm{NO}^{\bullet}$ was reinforced in the presence of $20 \mu \mathrm{m}$ of arginine and was abolished by the addition of $20 \mathrm{mM}$ of L- $N$-omega-nitro-L-arginine methyl ester. In physiological conditions the endothelium regulates the 
vascular tone ${ }^{52}$ by producing some $1-10 \mu \mathrm{M}$ of $\mathrm{NO}{ }^{\bullet}$ and $1 \mathrm{nM}$ of anion superoxide (one of the contracting factors). The intravascular half-life of $\mathrm{NO}^{\bullet}$ is about 2 msec with a strictly localized consumption so that the likelihood of improving vasodilation in remote ischemic areas (the macula or the limbs) seems negligible. However, $\mathrm{NO}^{\bullet}$ readily reacts with GSH, cysteine, albumin and hemoglobin (cysteine residue $\beta$ 93) and the formed $S$-nitrosothiols and $S$-nitrosohemoglobin have half-lives of 5-50 min, allowing a pharmacological effect at distant sites. ${ }^{53,54}$ It remains to be ascertained whether ozonated blood enhances the release of prostacyclin $\left(\mathrm{PGI}_{2}\right)$ and angiopoietins, both important factors for improving ischemic vasculopathies.

\section{Parenchymal cells in other organs}

Upon reinfusion of ozonated blood, LOPs can reach other organs such as the hypothalamus, endocrine glands, liver, kidneys and bone marrow. The phenomenon of adaptation to the repeated and acute oxidative stress imposed by $\mathrm{O}_{3}$-AHT is most interesting and able to elicit crucial therapeutic responses. During prolonged treatment, cells throughout the body receive small and gradual pulses of LOPs that are responsible for: (1) neuro-endocrine responses explaining the reported feeling of wellness, ${ }^{55}$ (2) the upregulation of antioxidant enzymes in several cell types that is an excellent way to re-equilibrate the oxidant-antioxidant unbalance, and (3) inducing a number of stress or heat shock proteins (HSPs) such as HSP27, HO-1 (HSP 32), HSP72 and HSP90. ${ }^{56-59}$ We are particularly interested in HO-1 because this is a protective enzyme allowing the formation of $\mathrm{Fe}^{2+}$, bilirubin (an antioxidant) and carbon monoxide $(\mathrm{CO})$, a vasodilator that, like $\mathrm{NO}^{\bullet}$, increases the level of cyclic guanosine monophosphate, the reaction catalyzed by guanylate cyclase.

Besides gases produced by the gut flora, it is truly remarkable that cells can release other gaseous molecules $\left(\mathrm{NO}{ }^{\bullet}, \mathrm{CO}\right.$ and $\mathrm{CO}_{2}$ ), and it is even more surprising that even ozone can be produced by activated antibody-coated neutrophils. ${ }^{60}$ These gases can now be considered as molecules able to deliver crucial physiological and pharmacological effects. Excessive amounts of these molecules are toxic, causing serious pathological events and possibly death. Nature teaches us that these gases, depending on their concentrations, can be either friends or foes and, similarly, ozone therapy can be either useful or toxic. If this reasoning is correct, ozone therapy, when judiciously performed, is a simple, inexpensive and atoxic approach with the advantage of activating several biomechanisms in different cells unusually leading to an integrated and often incredible response.

\section{The extreme versatility of ozone therapy}

The sarcastic comment of the opponents is that ozone therapy looks like a panacea for all diseases. Indeed it seems so, but in reality this is due to the multitude of compounds originated at first from the reaction of ozone with body fluids, and eventually able to display pleiotropic effects delivered by different organs. For the sake of brevity I can only summarize the therapeutic effects so far reported.

\section{Acute and chronic bacterial, viral and fungine infections}

Intuitively, ozone therapy is very useful in both acute and chronic bacterial, viral and fungine infections because the generated ROS are the natural and most effective agents to which even antibiotic resistant pathogens do not resist. ${ }^{3,61}$ Moreover, improvement of metabolism and immunological functions contribute to a favorable outcome. Abscesses, anal fissures, fistulae, bed sores, furunculosis, inveterate osteomyelitis, vulvovaginitis, necrotizing fasciitis and torpid ulcers of various origin have been shown to improve rapidly, particularly using the combination of $\mathrm{O}_{3}$-AHT with topical treatment using either direct $\mathrm{O}_{2}-\mathrm{O}_{3}$ exposure or the cleansing and stimulating effect of ozonated water and oil. The activity of ozonated solutions in eliminating the infectivity and enhancing healing is almost unbelievable. However, in Western countries accustomed to the use of antibiotic creams (often with corticosteroids) there is no mental attitude to profitably use the inexpensive and most active ozonated oil. ${ }^{62}$

\section{Ischemic diseases}

Chronic limb ischemia (atherosclerosis, diabetes, Burger's disease) is most effectively treated at stage II-b with complete disappearance of pain and claudication. Moreover, since 1981, Rokitansky et al. ${ }^{49}$ demonstrated that a cycle of $\mathrm{O}_{3}$-AHT (usually 14 treatments) led to a very good improvement in $70.6 \%$ and $53.8 \%$ of either stage III or stage IV (Fontaine) patients, respectively. Amputation of toes and limbs could be avoided in pre-terminal phases. These results have been amply confirmed by Giunta et al., ${ }^{63}$ Mattassi et al. ${ }^{64}$ and Tylicki et al. ${ }^{65}$ Preterminal patients with chronic heart ischemia and no further susceptibility to conventional treatments have shown marked improvement after a cycle of 14 treatments of extracorporeal circulation of blood against $\mathrm{O}_{2}-\mathrm{O}_{3}{ }^{66}$ A randomized controlled study is in progress for establishing the validity of this more invasive method than classical $\mathrm{O}_{3}$-AHT. 


\section{Age-related macular degeneration}

A 6-year study in 90 patients with the 'dry' form of ARMD has been carried out performing a cycle of 13-14 $\mathrm{O}_{3}$-AHT treatments. Mean distance best-corrected visual acuity was significantly improved in the treatment group of patients while in the control group, first treated with oxygenated autohaemotherapy, only a modest and not significant improvement in mean distance visual acuity was observed. No adverse effects have been noted and the patient's compliance has been excellent. ${ }^{26}$ Owing to the constant increase of ARMD patients and the lack of an effective conventional treatment, this approach appears mandatory.

\section{Orthopedic diseases}

Until recently it was unthinkable that a mixture of $\mathrm{O}_{2}-\mathrm{O}_{3}$ could be useful in orthopedics. Indeed lumbar disk herniation and osteoarthritis, although having different etiologies, have a common inflammatory background expressed by a localized chronic oxidative stress due to excessive production of ROS, release of proinflammatory cytokines and activation of cycloxygenases. Common sense would proscribe the use of ozone, a master generator of free radicals and, as it is well shown, ${ }^{34,67}$ after pulmonary exposure, a superb inflammatory agent. Contrary to all expectations, it is now well demonstrated ${ }^{68}$ that combined intradiscal and periganglionic injection of medical ozone allows an excellent outcome in 70.3\% of patients treated for disk herniation performed after conservative management failed to respond. In the same vein, it appears very surprising that the application of medical ozone in acute and chronic painful diseases of the joints allows rapid pain relief, disappearance of inflammation and improvement of mobility. Thousands of patients have been successfully treated and the lack of side effects is noteworthy. ${ }^{69}$

These positive empiric observations need to be explained. Ozone is indeed a surprising gas that paradoxically, after prolonged administration at low concentrations, induces tolerance, a phenomenon termed 'hormesis' by Goldman ${ }^{70}$ to indicate 'a beneficial effect of a low level exposure to an agent that is harmful at high levels'. Thus, at this stage, I use the definition of 'ozone paradox' for explaining these excellent therapeutic results. Immediately after $\mathrm{O}_{2}-\mathrm{O}_{3}$ administration in the nucleus pulposus, or into inflamed endoarticular cavities, a sort of oxidative shock seems to subvert all the traditional rules by inducing an antioxidative response due to several factors, among which is the cholinergic antiinflammatory pathway. $^{71}$ A detailed discussion is reported elsewhere. ${ }^{3}$

\section{Dentistry}

This is another medical specialty where ozone has been recently evaluated with exceedingly interesting results. $^{72}$ Primary root carious lesions are being treated with a novel ozone delivery system able to avoid any toxic risk for the mouth cavity and lungs. The tooth's lesion is exposed for 10-20 sec to a sort of ozone 'hurricane' based on a gas flow of $615 \mathrm{ml} / \mathrm{min}$ of $\mathrm{O}_{2}-\mathrm{O}_{3}$ at a low concentration ( $4 \mu \mathrm{g} / \mathrm{ml}$ ), perfectly enclosed in a tightly fitting silicone cup enclosing the tooth. It is not surprising that all bacteria, particularly lactobacilli, are destroyed so that the ozone-sterilized dental surface becomes quickly remineralized, becoming hard and resistant to further bacterial attack. This new approach is simple, inexpensive and well tolerated, as opposed to the conventional and painful 'drilling and filling' management of primary root carious lesions.

\section{Dermatological, pulmonary, renal, hematological and neurodegenerative diseases}

Owing to the ability of ozone to activate a number of biological targets, ozone therapy could be proficiently used in some dermatological, pulmonary, renal, hematological and neurodegenerative diseases. However these pathologies so far have not been evaluated in a controlled fashion. Most of the patients with metastatic cancer resistant to radiotherapy and chemotherapy report a striking improvement of the quality of life with prolonged (twice weekly for months) $\mathrm{O}_{3}$-AHT treatments. ${ }^{25,73}$ This is a constantly observed result, most probably due to a multifactorial neuroendocrine response.

\section{Summary}

Finally it must be emphasized that if ozone is judiciously used according to precisely defined guidelines, it causes neither acute, nor chronic side effects. After two decades of practical applications and the results observed in patients after conventional remedies have proved unsatisfactory, one has the feeling that, if ozone therapy could be accepted and used in all hospitals, it would represent a small but important medical revolution able to cure or stabilize several diseases in many patients in both rich and poor countries.

\section{Discussion and conclusions}

There is no doubt that ozone can be toxic, and even today its hazardous employment by charlatans and unprepared physicians has contributed to a poor 
consideration of ozone therapy. That is one reason why the use of ozone is prohibited in some states of the USA and why this therapy is still regarded with skepticism by orthodox medicine even in Germany, where this approach was first conceived. Moreover, the following data tend to generalize that ozone is always toxic and should not be used in medicine:

1. Overwhelming evidence shows that the bronchial-pulmonary system is very sensitive to ozone and this gas should never be inhaled. ${ }^{67}$

2. This is very true because the respiratory tract lining fluid is constituted by a very thin, watery film containing a minimal amount of antioxidants that makes mucosal cells extremely vulnerable to oxidation. The opposite situation occurs for blood cells suspended in plasma, which has a potent antioxidant capacity $(1.23-1.83 \mathrm{mmol} / \mathrm{l})$ able to tame any ozone dose within the therapeutic range $(10-80 \mu \mathrm{g} / \mathrm{ml})$.

3. Saline-washed erythrocytes suspended in saline undergo extensive hemolysis after ozone exposure. ${ }^{12}$

4. Cells in culture, even if exposed to very low ozone concentrations for a long time, undergo apoptosis. ${ }^{74}$

5. One-hour exposure of saline-diluted blood to $5 \mathrm{mM}$ of ozone induces genotoxic effects on leukocyte. ${ }^{75}$

\section{But is ozone always toxic?}

As a matter of fact millions of $\mathrm{O}_{3}$-AHT, even if performed in an empirical fashion during the past three decades, has neither yielded acute nor chronic toxic effects. According to Jacobs ${ }^{76}$ this procedure has yielded the lowest number of medical complications. However, four deaths have been recorded due to pulmonary embolism, which occurred during direct intravenous administration of $\mathrm{O}_{2}-\mathrm{O}_{3}$, an application prohibited by the European Society of Ozonetherapy since 1983. Thus ozone seems like Janus and his two faces require an explanation. This is now reasonably clear. Since 1988 we have investigated the problem in a scientific way using precise ozone generators, which allow checking ozone concentration in real time by a photometer calibrated with the classical iodometric method. A review ${ }^{61}$ and a critical book ${ }^{3}$ have extensively clarified the issue but this does not seem sufficient to dispel the dogma that 'Ozone is always toxic'. However, we now consider ozone as a real drug that must be used with caution after having carefully defined its therapeutic window. First, the ozone must be calibrated against the antioxidant capacity of the patient's blood in order to control the potential ozone toxicity.
Second, expert scientists in free radicals ought to distinguish the chronic intracellular oxidative stress typical of several pathologies by the transitory ( 5 min) calculated oxidative stress occurring when a precise volume of blood is exposed ex vivo to an equal volume of gas $\left(\mathrm{O}_{2}+\mathrm{O}_{3}\right)$ with well-defined ozone concentrations ranging from 20 up to $40 \mu \mathrm{g} / \mathrm{ml}$ per $\mathrm{ml}$ of blood. It needs to be emphasized that the exogenous oxidative stress caused by ozone in blood is due to the fact that ozone, once dissolved in the plasmatic water, instantaneously reacts with biomolecules and disappears but generates ROS, among which are $\mathrm{H}_{2} \mathrm{O}_{2}$ and LOPs. These are the effective ozone messengers that interact with a variety of cells and elicit the now-termed 'therapeutic shock' due to the multiform biological responses. That ozone acts as a real chemical drug is proved by the fact that the ozone messengers, to be effective, must reach a threshold because otherwise there are no biological effects and the therapeutic results, if any, are due to a placebo effect. Although we have proven that ozone therapy is not a nebulous approach and has been shown amenable to a precise scientific scrutiny, it is probable that much still remains to be uncovered.

Everyone knows that plasma and blood cells contain an almost redundant antioxidant system made up of hydro-liposoluble compounds and antioxidant enzymes. During aging or pathologic conditions, this is not sufficient to correct the intracellular oxidative stress, but normally it is adequate to tame ozone toxicity while allowing the generation of ROS and LOPs. Thus all data emphasizing ozone toxicity can be easily dismissed because the following is now well proven:

1. Blood is a much more ozone-resistant 'tissue' than the respiratory tract that, for anatomic, biochemical and metabolic reasons, is always at a loss when exposed to ozone, and therefore it is wrong to extrapolate ozone toxicity for the pulmonary system to blood.

2. Washed and saline-resuspended erythrocytes, fully depleted of the plasmatic antioxidants, are obviously very sensitive to ozonation, and all of these unnatural data have neither physiological nor practical significance.

3. The same occurs for cells cultured in antioxidant-poor media and exposed continuously for days to ozone. Surprisingly, cell biologists reported only the ozone concentration but have neither calculated nor taken into account the cumulative dose of ozone that after a long exposure kills the cells.

4. The conclusion is that, although ozone is potentially mutagenic, so far all experimental data performed in physiological condi- 
tions and clinical evidence have neither shown any cell damage nor adverse effects in patients. As a matter of fact, blood is exposed to ozone concentrations $(0.21-1.68$ $\mathrm{mM})$ lower than the mutagenic ones (1.5$5.6 \mathrm{mM})$. The question of whether ozone is genotoxic and mutagenic is a critical one and has been extensively discussed elsewhere. $^{3}$ What has never been entirely appreciated is the fact that we can only use an ozone dose that does not overwhelm the antioxidant capacity of blood.

Hopefully this discussion should put an end to the confusion between the endogenously constant oxidative stress due to the oxygen and the transitory and occasional therapeutic 'shock' due to precise blood ozonation. A point that should not be overlooked is that ozone messengers, by acting on different cells, elicit a variety of biological effects that cannot ever be dreamed of with the usual reductionist approach of using a drug for a single target. This consideration can explain the far superior therapeutic effect of parenteral and topical ozone therapy in advanced cases of chronic limb ischemia to the conventional infusion of prostanoids. Another relevant characteristic is that the judicious strategy 'start low, go slow' in using ozone is able to induce in patients the adaptation to the chronic oxidative stress (i.e. ozone) paradoxically upregulates the antioxidant defenses. The scientific evaluation of ozone therapy efficacy remains the crucial point: results accrued during the past 20 years show that is very useful in chronic limb ischemia, ARMD, chronic infectious diseases and, most surprising, in orthopedics and even in dentistry after conventional medicine has failed to provide a real advantage. There are no adverse effects and most of the patients report a feeling of wellness. The efficacy remains uncertain in other pathologies such as neurodegenerative, autoimmune diseases and cancer because clinical experience is fragmentary and anecdotal. However, orthodox medicine remains skeptical because controlled clinical trials are few and are not considered satisfactory. Unfortunately our good will is not sufficient to overcome prejudice and lack of sponsors. It is distressing to realize that a wrong dogma, commercial interests and the disinterest of Health Authorities delay the application of a medical approach that could help billions of patients, particularly in poor countries.

Finally, this paper may serve the purpose of opening a fruitful discussion on the beneficial versus the toxicological actions of ozone, and a referee has proposed that the debate may be hosted as a forum by Mediators of Inflammations.

ACKNOWLEDGEMENTS. This work was in small part supported by the Medical Science Technology Corporation, Winchester, UK. The author wishes to thank Dr C. Aldinucci, Dr L. Bianchi, Dr E. Borrelli, Dr F.
Corradeschi, Dr A. Larini, Dr L. Luzzi, Prof. L. Paulesu, Dr S. Silvestri and Dr G. Valacchi who have, at different times, contributed to clarify the ozone dilemma. The linguistic revision of Mrs Helen Carter is gratefully acknowledged.

\section{References}

1. Wehrli F, Steinbart H. Erfahrungen mit der Haematogenen OxydationsTherapie (HOT). Ars Medici 1954; 10: 44-51.

2. Wolff HH. Die Behandlung peripherer Durchblutungsstörungen mit Ozon. Erfahr Hk 1974; 23: 181-184

3. Bocci V. Oxygen-ozone Therapy. A Critical Evaluation, Dordrect: Kluwer Academic Publishers, 2002.

4. Esterbauer H, Schaur RJ, Zollner H. Chemistry and biochemistry of 4hydroxynonenal, malonaldehyde and related aldehydes. Free Radic Biol Med 1991; 11: 81-128.

5. Antunes F, Cadenas E. Estimation of $\mathrm{H}_{2} \mathrm{O}_{2}$ gradients across biomembranes. FEBS Lett 2000; 475: 121-126.

6. Stone JR, Collins T. The role of hydrogen peroxide in endothelial proliferative responses. Endothelium 2002; 9: 231-238.

7. Miller NJ, Rice-Evans C, Davies MJ, Gopinathan V, Milner A. A novel method for measuring antioxidant capacity and its application to monitoring the antioxidant status in premature neonates. Clin Sci 1993; 84: $407-412$

8. May JM, Qu Z-C, Whitesell RR, Cobb CE. Ascorbate recycling in human erythrocytes: role of GSH in reducing dehydroascorbate. Free Radic Biol Med 1996; 20: 543-551.

9. Mendiratta S, Qu ZC, May JM. Erythrocyte ascorbate recycling: antioxidant effects in blood. Free Radic Biol Med 1998; 24: 789-797.

10. Buege JA, Aust SD. Microsomal lipid peroxidation. Meth Enzymol 1978; 52: $302-310$.

11. Hu ML. Measurement of protein thiol groups and glutathione in plasma. Meth Enzymol 1994; 233: 380-385.

12. Goldstein BD, Balchum OJ. Effect of ozone on lipid peroxidation in the red blood cell. Proc Soc Exp Biol Med 1967; 126: 356-358.

13. Freeman BA, Miller BE, Mudd JB. Reaction of ozone with human erythrocytes. In: Lee SD, Mudd JB, eds. Assessing Toxic Effects of Environmental Pollutants, Ann Arbor, MI: Ann Arbor Science Publishers, 1979: $151-171$

14. Uppu RM, Cueto R, Squadrito GL, Pryor WA. What does ozone react with at the air/lung interface? Model studies using human red blood cell membranes. Arch Biochem Biophys 1995; 319: 257-266.

15. Gòrnicki A, Gutsze A. In vitro effects of ozone on human erythrocyte membranes: an EPR study. Acta Biochim Pol 2000; 47: 963-971.

16. Shinriki N, Suzuki T, Takama K, Fukunaga K, Ohgiva S, Kubota K, Miura T. Susceptibilities of plasma antioxidants and erythrocyte constituents to low levels of ozone. Haematologia (Budap) 1998; 29: 229-239.

17. Bocci V, Luzzi E, Corradeschi F, Paulesu L, Rossi R, Cardaioli E, Di Simplicio P. Studies on the biological effects of ozone: 4. Cytokine production and glutathione levels in human erythrocytes. J Biol Regulat Homeost Agents 1993; 7: 133-138.

18. Bocci V, Valacchi G, Corradeschi F, Aldinucci C, Silvestri S, Paccagnini E, Gerli R. Studies on the biological effects of ozone: 7. Generation of reactive oxygen species (ROS) after exposure of human blood to ozone. J Biol Regulat Homeost Agents 1998; 12: 67-75.

19. Clemens MR, Waller HD. Lipid peroxidation in erythrocytes. Chem Phys Lipids 1987; 45: 251-268.

20. Machlin LJ, Bendich A. Free radical tissue damage: protective role of antioxidant nutrients. FASEB J 1987; 1: 441-445.

21. Galleano M, Puntarulo S. Role of antioxidants on the erythrocytes resistance to lipid peroxidation after acute iron overload in rats. Biochim Biophys Acta 1995; 1271: 321-326.

22. Mudd JB, Dawson PJ, Santrock J. Ozone does not react with human erythrocyte membrane lipids. Arch Biochem Biophys 1997; 341: $251-$ 258 .

23. Zimran A, Wasser G, Forman L, Gelbart T, Beutler E. Effect of ozone on red blood cell enzymes and intermediates. Acta Haematol 1999; 102: $148-151$.

24. Cross CE, Motchnik PA, Bruener BA, Jones DA, Kaur H, Ames BN Halliwell B. Oxidative damage to plasma constituents by ozone. FEBS Lett 1992; 298: 269-272.

25. Bocci V, Larini A, Micheli V. A constant restoration of normoxia may control neoplastic growth. A reappraisal of an old approach.Cancer Invest 2004; in press.

26. Diadori A, Bocci V, Carraro F, et al. Ozonetherapy and age-related macular degeneration: a pilot study. In: Ceccherelli F, Giron F, eds. L'Ozonoterapia nel 2000, Torino: Edizioni Libreria Cortina, 2000: $33-$ 45.

27. Viebahn R. The Use of Ozone in Medicine, Iffezheim: ODREI Publishers, 1999: $1-148$.

28. Akioka K, Shiratori R, Kaneko Y, Ogawa S. Mechanisms of action of ozone in maintaining energy metabolism in hemorrhagic shock. Nibon Univ J Med 2002; 44: 123-133. 
29. Bocci V, Paulesu L. Studies on the biological effects of ozone 1 Induction of interferon gamma on human leucocytes. Haematologica 1990; 75: 510-515.

30. Bocci V, Luzzi E, Corradeschi F, Paulesu L, Di Stefano A. Studies on the biological effects of ozone: 3. An attempt to define conditions for optimal induction of cytokines. Lymphokine Cytokine Res 1993; 12 $121-126$.

31. Bocci V, Valacchi G, Corradeschi F, Fanetti G. Studies on the biological effects of ozone: 8. Effects on the total antioxidant status and on interleukin-8 production. Mediat Inflamm 1998; 7: 313-317.

32. Arsalane K, Gosset P, Vanhee D, Voisin C, Hamid Q, Tonnel AB, Wallaert B. Ozone stimulates synthesis of inflammatory cytokines by alveolar macrophages in vitro. Am J Respir Cell Mol Biol 1995; 13: 60-68.

33. Van Hoof HJM, Zijlstra FJ, Voss H-P, Garrelds IM, Dormans JAMA, Van Bree L, Bast A. The effect of ozone exposure on the release of eicosanoids in guinea-pig BAL fluid in relation to cellular damage and inflammation. Mediat Inflamm 1997; 6: 355-361.

34. Bayram H, Sapsford RJ, Abdelaziz MM, Khair OA. Effect of ozone and nitrogen dioxide on the release of proinflammatory mediators from bronchial epithelial cells of nonatopic nonasthmatic subjects and atopic asthmatic patients in vitro. J Allergy Clin Immunol 2001; 107: 287-294.

35. Cho HY, Zhang LY, Kleeberger SR. Ozone-induced lung inflammation and hyperreactivity are mediated via tumor necrosis factor-alpha receptors. Am J Physiol Lung Cell Mol Physiol 2001; 280: L537-L546.

36. Reth M. Hydrogen peroxide as second messenger in lymphocyte activation. Nat Immunol 2002; 3: 1129-1134.

37. Verma IM, Stevenson J. IkappaB kinase: beginning, not the end. Proc Natl Acad Sci USA 1997; 94: 11758-11760.

38. Soberman RJ. The expanding network of redox signaling: new observations, complexities, and perspectives. J Clin Invest 2003; 111 $571-574$

39. Bocci V, Luzzi E, Corradeschi F, Paulesu L. Studies on the biological effects of ozone: 5. Evaluation of immunological parameters and tolerability in normal volunteers receiving ambulatory autohaemotherapy. Biotherapy 1994; 7: 83-90

40. Hernandez F, Menendez S, Wong R. Decrease of blood cholesterol and stimulation of antioxidative response in cardiopathy patients treated with endovenous ozone therapy. Free Radic Biol Med 1995; 19: $115-$ 119 .

41. Bocci V. Does ozone therapy normalize the cellular redox balance? Med Hypotheses 1996; 46: 150-154.

42. Sharma YK, Davis KR. The effects of ozone on antioxidant responses in plants. Free Radic Biol Med 1997; 23: 480-488

43. León OS, Menéndez S, Merino N, et al. Ozone oxidative preconditioning: a protection against cellular damage by free radicals. Mediat Inflamm 1998; 7: 289-294.

44. Csonka C, Pataki T, Kovacs P, Muller SL, Schroeter ML, Tosaki A, Blasig IE. Effects of oxidative stress on the expression of antioxidative defense enzymes in spontaneously hypertensive rat hearts. Free Radic Biol Med 2000; 29: 612-619.

45. Maresca M, Colao C, Leoncini G. Generation of hydrogen peroxide in resting and activated platelets. Cell Biochem Funct 1992; 10: 79-85.

46. Iuliano L, Colavita AR, Leo R, Praticò D, Violi F. Oxygen free radicals and platelet activation. Free Radic Biol Med 1997; 22: 999-1006.

47. Bocci V, Valacchi G, Rossi R, Giustarini D, Paccagnini E, Pucci AM, Di Simplicio P. Studies on the biological effects of ozone: 9 . Effects of ozone on human platelets. Platelets 1999; 10: 110-116.

48. Valacchi G, Bocci V. Studies on the biological effects of ozone: 10 . Release of factors from ozonated human platelets. Mediat Inflamm 1999; 8: 205-209.

49. Rokitansky O, Rokitansky A, Steiner J, Trubel W, Viebahn R, Washüttl J. Die Ozontherapie bei peripheren, arteriellen Durchblutungs-störungen; klinik, biochemische und blutgasanalytische Untersuchungen. In: Wasser IOA, Berlin: Ozon-Weltkongress, 1981: 53-75.

50. Werkmeister H. Dekubitalgeschwüre und die Behandlung mit der OzonUnterdruckbegasung. In: Beck EG, Viebahn-Hänsler R, eds. OzonHandbuch. Grundlagen. Prävention. Therapie, Landsberg: Ecomed, 1995: V-7.1 1-V-7.1 22

51. Valacchi G, Bocci V. Studies on the biological effects of ozone: 11. Release of factors from human endothelial cells. Mediat Inflamm 2000 9: $271-276$.
52. Wink DA, Grisham MB, Mitchell JB, Ford PC. Direct and indirect effects of nitric oxide in chemical reactions relevant to biology. Methods Enzymol 1996; 268: 12-31.

53. Jia L, Bonaventura C, Bonaventura J, Stamler JS. S-nitrosohaemoglobin: a dynamic activity of blood involved in vascular control. Nature 1996; 380: $221-226$.

54. Pawloski JR, Hess DT, Stamler JS. Export by red blood cells of nitric oxide bioactivity. Nature 2001; 409: 622-626.

55. Benson H, Friedman R. Harnessing the power of the placebo effect and renaming it 'remembered wellness'. Annu Rev Med 1996; 47: 193-199.

56. Snyder SH, Baranano DE. Heme oxygenase: a font of multiple messengers. Neuropsychopharmacology 2001; 25: 294-298.

57. Lee TS, Chau LY. Heme oxygenase- 1 mediates the anti-inflammatory effect of interleukin-10 in mice. Nat Med 2002; 8: 240-246.

58. Hamilton KL, Staib JL, Phillips T, Hess A, Lennon SL, Powers SK. Exercise, antioxidants, and HSP72: protection against myiocardial ischemia/reperfusion. Free Radic Biol Med 2003; 34: 800-809.

59. Wagner M, Cadetg P, Ruf R, Mazzucchelli L, Ferrari P, Redaelli CA. Heme oxygenase-1 attenuates ischemia/reperfusion-induced apoptosis and improves survival in rat renal allografts. Kidney Int 2003; 63: 1564impro

60. Babior BM, Takeuchi C, Ruedi J, Gutierrez A, Wentworth P. Investigating antibody-catlyzed ozone generation by human neutrophils. Proc Natl Acad Sci USA 2003; 100: 3031-3034.

61. Bocci V. Biological and clinical effects of ozone. Has ozonetherapy a future in medicine? Br J Biomed Sci 1999; 56: 270-279.

62. Menéndez S, Falcon L, Simon DR, Landa N. Efficacy of ozonized sunflower oil in the treatment of tinea pedis. Mycoses 2002; 45: 329332 .

63. Giunta R, Coppola C, Luongo C, et al. Ozonized autohemotransfusion improves hemorheological parameters and oxygen delivery to tissues in patients with peripheral occlusive arterial disease. Ann Hematol 2001; 80: $745-748$.

64. Mattassi R, D'Angelo F, Bisetti P, Colombo R, Vaghi M. Terapia con ozono per via parenterale nelle arteriopatie obliteranti periferiche: meccanismo biochimico e risultati clinici. Il Giornale Di Chirurgia 1987; VIII: 109-111.

65. Tylicki L, Niewglowski T, Biedunkiewicz B, Burakoski S, Rutkows B. Beneficial clinical effects of ozonated autohemotherapy in chronically dialysed patients with atherosclerotic ischemia of the lower limbs-pilot study. Int J Artif Organs 2001; 24: 79-82.

66. Di Paolo N, Bocci V, Garosi G, et al. Extracorporeal blood oxigenation and ozonation (EBOO) in man. Preliminary report. Int J Artif Organs 2000; 23: $131-141$

67. Lippman M. Health effects of ozone, a critical review. J Am Air Pollut Control Assoc 1989; 39: 672-695.

68. Andreula CF, Simonetti L, De Santis F, Agati R, Ricci R, Leonardi M. Minimally invasive oxygen-ozone therapy for lumbar disk hernation. Am I Neuroradiol 2003; 24: 996-1000.

69. Siemsen CH. Ozon-Anwendung bei akuten und chronischen Gelenkerkrankungen. In: Beck EG, Viebahn-Hänsler R, eds. Ozon-Handbuch. Grundlagen. Prävention. Therapie, Landsberg: Ecomed, 1995: V-9.2 1V-9.2 14.

70. Goldman M. Cancer risk of low-level exposure. Science 1996; 271: $1821-1822$

71. Tracey KJ. The inflammatory reflex. Nature 2002; 420: 853-859.

72. Baysan A, Whiley RA, Lynch E. Antimicrobial effect of a novel ozonegenerating device on micro-organisms associated with primary root carious lesions in vitro. Caries Res 2000; 34: 498-501.

73. Bocci V. Ozonetherapy as a possible biological response modifier in cancer. Forsch Komplementärmed 1998; 5: 54-60.

74. Leist M, Raab B, Maurer S, Brigelius-Flohé R. Conventional cell culture media do not adequately supply cells with antioxidants and thus facilitate peroxide-induced genotoxicity. Free Radic Biol Med 1996; 21: $297-306$.

75. Dìaz-Llera S, Gonzàlez-Hernàndez Y, Prieto-Gonzàlez EA, Azoy A Genotoxic effect of ozone in human peripheral blood leukocytes. Mutat Res 2002; 517: 13-20.

76. Jacobs M-T. Untersuchung uber Zwischenfalle und typische Komplikationen in der Ozon-Sauerstoff-Therapie. OzoNachrichten 1982; 1: 5. 


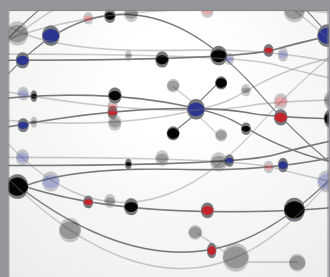

The Scientific World Journal
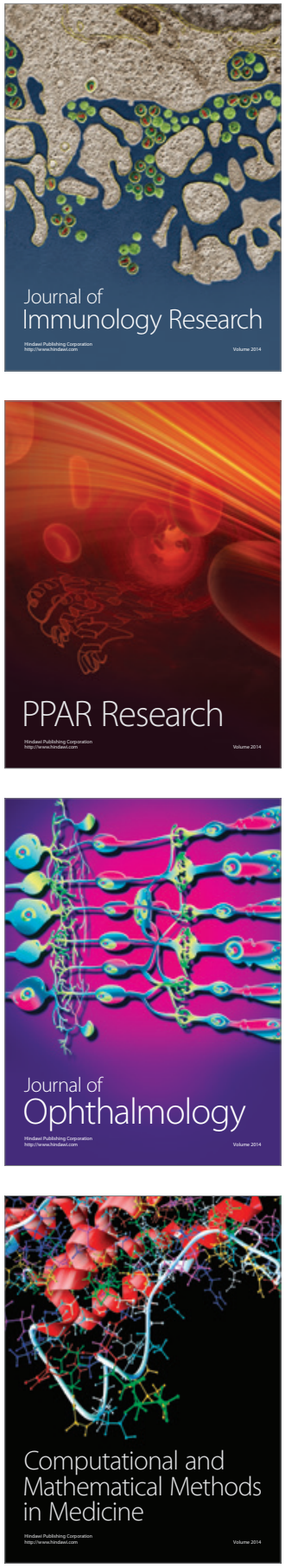

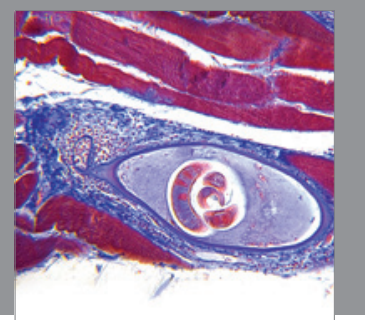

Gastroenterology

Research and Practice
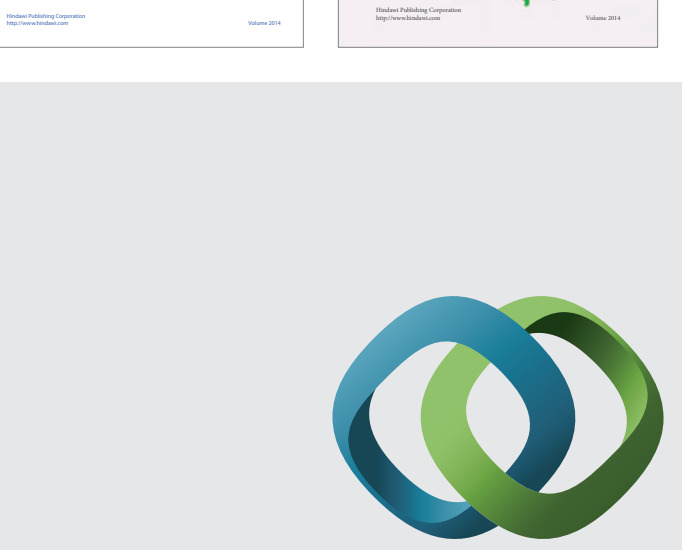

\section{Hindawi}

Submit your manuscripts at

http://www.hindawi.com
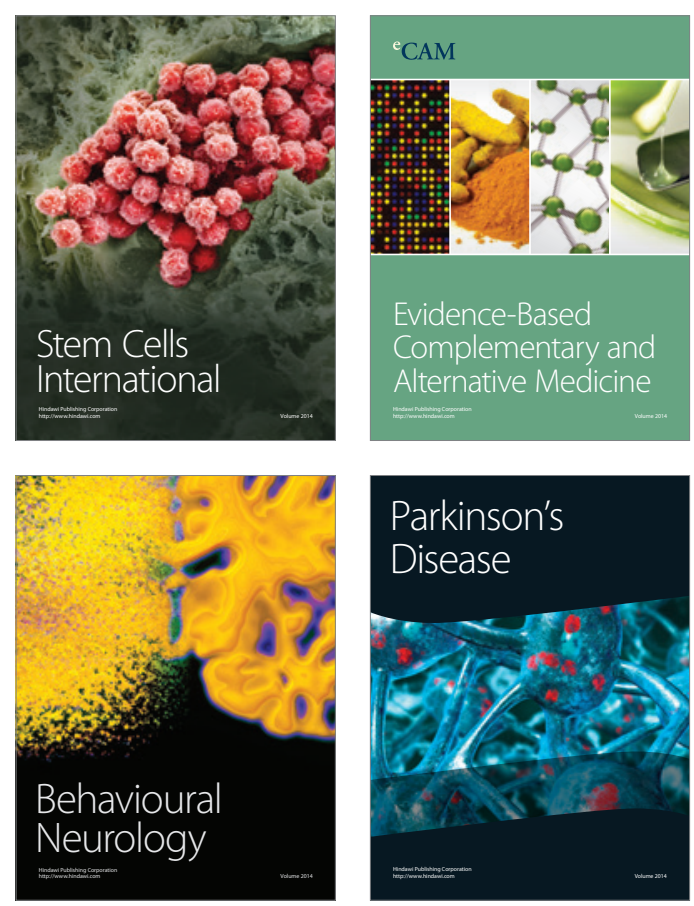

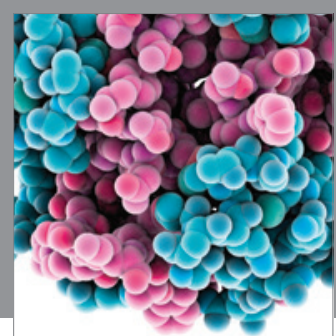

Journal of
Diabetes Research

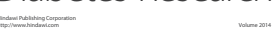

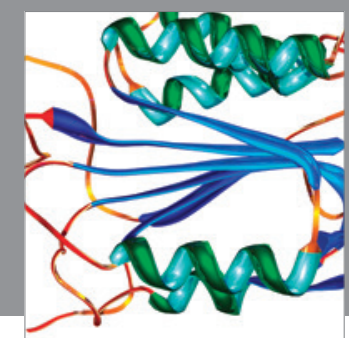

Disease Markers
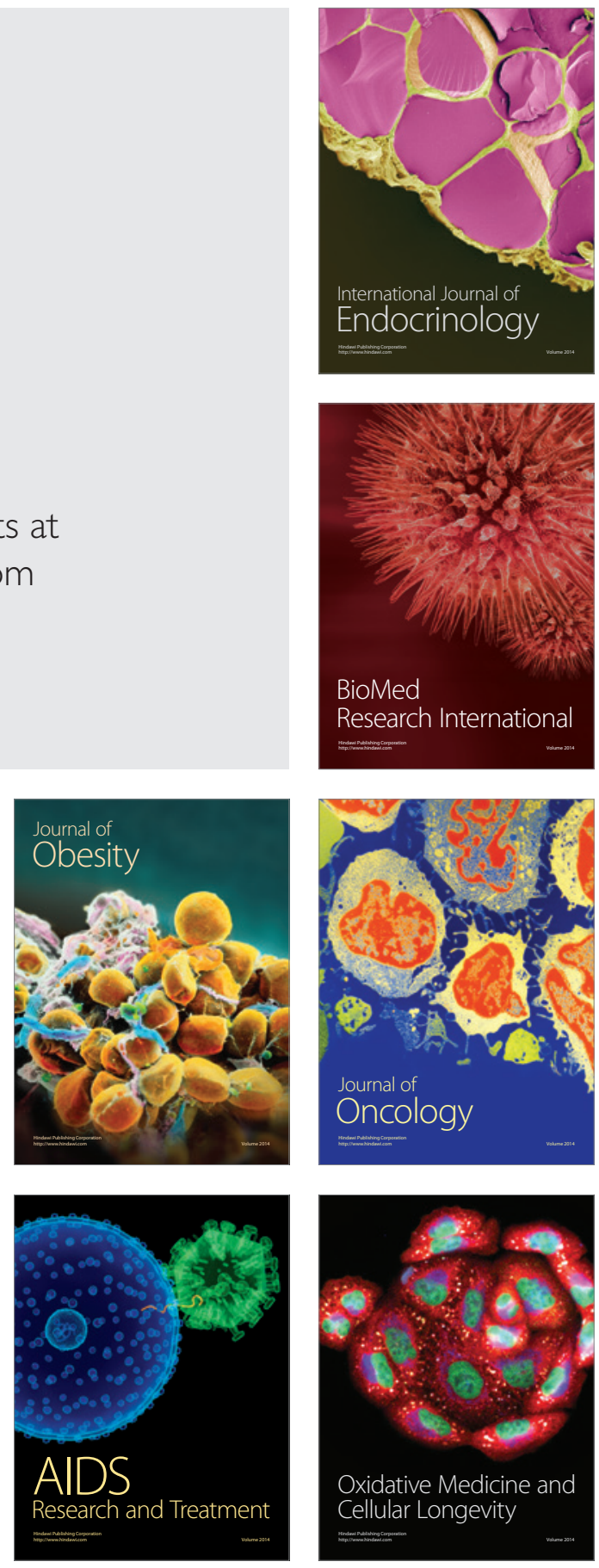